\title{
Editorial
}

\section{A New Mindset: Artificial Intelligence in Digital Hearing Aids}

\author{
Neha Taneja, MASLP, BSc* \\ Consultant Audiologist and Speech-Language Pathologist, India \\ "Corresponding author \\ Neha Taneja, MASLP, BSc \\ Consultant Audiologist and Speech-Language Pathologist, India
}

\section{Article information}

Received: April I ${ }^{\text {st }}$, 2020; Accepted: April I8 $8^{\text {th }}, 2020$; Published: May $8^{\text {th }}, 2020$

\section{Cite this article}

Taneja N. A new mindset:Artificial intelligence in digital hearing aids. Otolaryngol Open J. 2020; 6(I): el-e3. doi: I0. 17/40/OTLOJ-6-e007

\section{ARTIFICIAL INTELLIGENCE: GENERAL UNDERSTANDING}

A rtificial intelligence (AI) has a wider scope of its applications

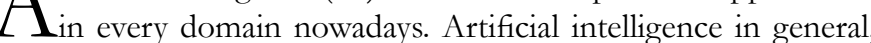
refers to the field of computer science which generates, uses computer programs to solve complex problems and provides intelligent solutions. ${ }^{1}$ For this procedure, several different rules, algorithms, and software can be used.

\section{ARTIFICIAL INTELLIGENCE: ROLE IN THE HEALTHCARE INDUSTRY}

When the healthcare industry is considered, AI has been used extensively. Techniques of AI assists physicians in clinical decision making i.e., radiology $y^{2}$ and tackling various disease ${ }^{2}$ such as can$\operatorname{cer}^{2,3}$ neurology $y^{2,4,5}$ and cardiology, ${ }^{2,6,7}$ Analysis of big data can be easily obtained by the clinician into a required clinical chunk of data by techniques used in $\mathrm{AI} .^{2}$ Additionally, the big success of $\mathrm{AI}$ in medical literature ${ }^{2}$ has been in segregating larger chunks of relevant clinical data from large medical records of patients via the use of sophisticated algorithms which may help in achieving efficient clinical decision-making., ${ }^{2,8}, \mathrm{AI}$ helps further to physicians to render quality patient care by chunking larger updated information from various sources such as textbooks, clinical practices, and journals. ${ }^{2,10}$ In addition, AI technology helps in better medical results with fewer errors in - diagnostic and therapeutic as evidenced more with humans clinical practice. ${ }^{2,6,11}$

\section{ARTIFICIAL INTELLIGENCE - ROLE IN HEARING HEALTHCARE INDUSTRY (AMPLIFICATION DEVICES)}

In a similar trend in the hearing healthcare industry, artificial intel- ligence has been found to be widely in use. ${ }^{2}$ Artificial intelligence with reference to amplification devices - digital hearing aids can be understood as a vehicle or platform which facilitates audibility and assists in communication via the use of advanced algorithm and software. With the advancement in technology from analog to digital, listening performance has been enhanced for hearing impaired users. But the standard term "digital" doesn't imply all digital hearing aids are the same. ${ }^{1}$ They differ in terms of the technology used and hence fall into essential, advanced and premium series. Premium quality in every brand of hearing aids refers to enhanced performance series with multiple advanced features. It incorporates that feature which makes the hearing aid smart, intelligent for its users and here comes in the AI. This new platform assists in the superior performance of hearing aids with respect to real-time acoustic demands. Hearing- impaired patient's experiences various listening situations which may be at times predictable, repeated and or real-time varying or combination of all. In such different situations, signal and noise may not be same all the time. The level of sound and competing signals fluctuates from time to time. Traditional amplification devices were limited to meet such challenging and varying acoustic needs. With the development of technology with digital hearing aids, hearing impaired patients become handy with AI technology. ${ }^{1,12}$ These techniques may facilitate the use of features and programs to users and enable them to perform better in noisy conditions with the added performance of directionality cues. For communication to be an effective significant signal to noise ratio ( $\mathrm{S} / \mathrm{N}$ Ratio) has to be maintained. According to previous research ${ }^{1,13} \mathrm{~S} / \mathrm{N}$ ratio has been reported to be a major challenge for effectiveness of communication, especially by sensorineural hearing-impaired patients. The overall sound level over noise is crucial for the understanding of the message. It has been reported in the literature that hearing-impaired individuals may perceive appropriately with $\mathrm{S} / \mathrm{N}$ ratios of +14 to $+30 \mathrm{~dB}$ for 
communication. ${ }^{1}$ Louder the background noise, sound signal less effective and reception deteriorates.

Does the major question arise now as to how does digital hearing aids incorporating AI techniques perform so intelligently? AI incorporates two significant approaches ${ }^{1,14}$ termed as classical approach and statistical approaches. Classical approaches work based on a predetermined rule structure to analyze input signals to derive output. On the contrary a Statistical approach incorporates analysis of larger sets of data to find patterns and make conclusions for its general applicability. The classical approach has been majorly used in hearing aids programming considering practical aspects of hearing aid users. ${ }^{1}$ The rules of this approach are explicit. For deriving the output from a varying situation it has set rules which can easily compare the inputs and gives an output. On the contrary statistical approaches are not explicit which requires the user to hear parallel different potential solutions in the acoustic environment to decide upon the desired output. This may not be feasible for patients in real time-varying acoustic environments that they may thousands of trials in a given setting and decide upon a solution or an output. Hence this approach limits its application for hearing aid programming.

\section{CONCLUSION}

Artificial intelligence has more benefits over its limitations, as it assists the users to handle complex situations in real-time via the rulebased system and not prediction in isolation. AI technology opens a gateway to allow the usage of complex algorithms and software for problem-solving. AI technology is good, relevant and meant to help hearing-impaired people and it's not just technology of bits and bytes. These computer-assisted applications make routines work very easier and save lots of time. Hearing aid users can be benefited to communicate more effectively via the use of different advanced features and programs which work actively in a real- time acoustic environment. The key component of communication i.e., $\mathrm{S} / \mathrm{N}$ ratio is taken care of effectively thus helping hearing aid users to hear better and understand speech. Professionals can confidently recommend the amplification devices to their patients. The limitations of $\mathrm{AI}$ are that though these computer-assisted technologies can effectively fasten daily routine works but cannot mimic human bestowed property of cognition, ${ }^{1}$ thinking, ${ }^{1,15}$ language processing and social interaction. ${ }^{16}$ Owing to its many advantages AI through its applications are accepted world-wide.

\section{CONFLICTS OF INTEREST |}

The author declares there is NO conflict of interest

\section{REFERENCES}

1. Schum DJ. Artificial intelligence: The new advanced technology in hearing aids Web site. https://www.audiologyonline.com/ articles/artificial-intelligence-new-advanced-technology-1082. Accessed March 31, 2020.

2. Jiang F, Jiang Y, Zhi H, Dong Y, Li H, Ma S, et al. Artificial in- telligence in healthcare: Past, present and future. Stroke and Vascular Neurology. 2017; 2(4): 230-243. doi: 10.1136/svn-2017-000101

3. Somashekhar SP, Kumarc R, Rauthan A, et al. Abstract S6-07: double blinded validation study to assess performance of IBM artificial intelligence platform, Watson for oncology in comparison with manipal multidisciplinary tumour board - first study of 638 breast Cancer cases. Cancer Res. 2017; 77(4 Suppl): S6-S7. doi: 10.1158/1538-7445.SABCS16-S6-07

4. Bouton CE, Shaikhouni A, Annetta NV, Bockbrader MA, Friedenberg DA, Nielson DM, et al. Restoring cortical control of functional movement in a human with quadriplegia. Nature. 2016; 533: 247-250. doi: 10.1038/nature17435

5. Farina D, Vujaklija I, Sartori M, Kapelner T, Negro F, Jiang N, et al. Man/machine interface based on the discharge timings of spinal motor neurons after targeted muscle reinnervation. Nat Biomed Eng. 2017; 1: 25. doi: 10.1038/s41551-016-0025

6. Dilsizian SE, Siegel EL. Artificial intelligence in medicine and cardiac imaging: harnessing big data and advanced computing to provide personalized medical diagnosis and treatment. Curr Cardiol Rep. 2014; 16: 441. doi: 10.1007/s11886-013-0441-8

7. Marr B. First FDA approval for clinical Cloud-Based Deep Learning in Healthcare Web site. https://www. forbes. com/ sites/ bernardmarr/ 2017/ 01/ 20/ first- fda- approval- for- clinical- cloud- based- deep- learning- inhealthcare/\# 7a0ed8dc161c. Accessed June 1, 2017.

8. Murdoch TB, Detsky AS. The inevitable application of big data to health care. JAMA. 2013; 309: 1351-1352. doi: 10.1001/ jama.2013.393

9. Kolker E, Özdemir V, Kolker E. How healthcare can refocus on its super-customers (patients, $\mathrm{n}=1$ ) and customers (doctors and nurses) by leveraging lessons from amazon, uber, and watson. $O M$ ICS. 2016; 20: 329-333. doi: 10.1089/omi.2016.0077

10. Pearson T. How to replicate Watson hardware and systems design for your own use in your basement Web site. https://www. ibm. com/ developerworks/ community/ blogs/ InsideSystemStorage/ entry/ibm_watson_how_to_build_your_own_watson_jr_in_your_basement7? lang= en. Accessed June 1, 2017.

11. Patel VL, Shortliffe EH, Stefanelli M, Szolovits P, Berthold MR, Bellazzi R, et al. The coming of age of artificial intelligence in medicine. Artif Intell Med. 2009; 46: 5-17. doi: 10.1016/j. artmed.2008.07.017

12. Newell A. Fairy tales. AI Magazine. 1992; 13 (4): 46-48. doi: 10.1609/aimag.v13i4.1020

13. Pearson K, Bennett R, Fidell S. Speech levels in various environments. cfpub Web site. https://cfpub.epa.gov/si/si_public_record_Report.cfm?Lab=ORD\&dirEntryID $=45786$. Accessed June 
$1,2017$.

14. Champandard A. Artificial intelligence plain and simple: Approaches aidepot Web site. http://www.aidepot.com/. Accessed June 1, 2017.

15. McCarthy, J. What is Artificial Intelligence? formal.stanford
Web site. www.formal.stanford.edu/jmc/whatisai/whatisai.html. Accessed June 1, 2017.

16. Moravec H. When will computer hardware match the human brain? Journal of Evolution and Technology. 1998; 1. 